\title{
Formulating Palm-based Nanoemulsion in Room Temperature Ionic Liquids
}

\author{
${ }^{1}$ Tuan Nurul Azura Tuan Kob Yaakub, ${ }^{1}$ Mohd Basyaruddin Abdul Rahman and \\ ${ }^{1,2}$ Muhammad Alif Mohammad Latif \\ 'Department of Chemistry, \\ ${ }^{2}$ Center of Foundation Studies for Agricultural Science, Faculty of Science, \\ Universiti Putra Malaysia (UPM), 43400 Serdang, Selangor, Malaysia, aliflatif@upm.edu.my
}

\begin{abstract}
The ability of Room Temperature Ionic Liquids (RTLs) to support the self-aggregation of amphiphilic molecules such as non-ionic surfactants have enhanced their applications in the industry. The aim of the present study is to formulate and investigate the properties of surfactant/RTILs and surfactant/RTILs/oil aggregation intended for separation processes. The aggregation behaviour of a non-ionic surfactant, Tween80 in 1-butyl-3-methylimidazolium hexafluorophosphate $\left(\right.$ bmimPF $\left._{6}\right)$ and 1-butyl-3-methylimidazolium tetrafluoroborate $\left(\mathrm{bmimBF}_{4}\right)$ was determined by measuring the surface tension of surfactant/RTILs mixture at different concentration ratios. The resulting Critical Micelle Concentrations (CMCs) were compared with the

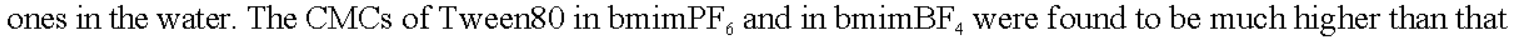
in water under the same condition. The relatively low solvophobicity between RTILs and the hydrophobic tail of Tween80 led to increased CMCs. The aggregation behaviour of Tween80 in RTILs was further investigated in the presence of an oil phase. The added Palm Oil Ester (POEs) induced the formation of oil-in-RTIL nanoemulsions. These nanoemulsions were prepared using low energy method and were characterized using Zetasizer measurement and transmission electron microscopy. The particle size of Tween $80 / \mathrm{bmimBF} / \mathrm{POE}$ were found comparable to the ones in water. The results showed that the introduction of oil phase produced a diverse effect towards hydrophobic and hydrophilic RTILs.
\end{abstract}

Key words: Nanoemulsion, room temperature ionic liquids, self-aggregation, introduction, hydrophobic, RTILs

\section{INTRODUCTION}

Ionic Liquids (ILs) are molten salts that are usually composed of both inorganic anion and an organic cation. Room Temperature ILs (RTILs) has the melting point below $100^{\circ} \mathrm{C}$ that is relatively lower than the melting point of water. Nowadays, RTILs has been used for many researches due to its variety of applications such as catalysis process (Van Rantwijk and Sheldon, 2007; Vafaeezadeh and Alinezhad, 2016), separation process (Flieger et al., 2014), organic synthesis (Wang et al., 2018) and electrochemistry (Wei and Ivaska, 2012; Shiddiky and Torriero, 2011; Stockmann et al., 2017). RTILs have become the interest of many types of research due to their physical and chemical properties. RTILs shows variation of structures based on the cation-anion combinations. For examples, there are imidazolium, pyrrolidinium, tetraalkylphosphonium, trialkylsulfonium and quaternary ammonium cations. The most commonly used cation in RTILs are the imidazolium-based cations. Surfactants are compounds that help to lower the surface tension between two immiscible liquids. As amphiphilic molecules, surfactants consist of a hydrophilic polar head group (non-ionic, anionic, cationic or zwitterion) and a hydrophobic hydrocarbon chain. Surfactants have special properties as they can aggregate and form micelles in aqueous solution and (in some cases) organic solvents. Moreover, it is found that RTILs was one of the solvents that can support the self-aggregation of amphiphilic molecules such as non-ionic surfactants (Greaves and Drummond, 2008). Hence, the self-aggregation of micelles in RTILs has been widely studied.

Theoretically, the driving force for the formation of surfactant self-aggregation is the adsorption of surfactants at the liquid surface that causes the decrease in the surface free energy of solutions (Piran et al., 2017). However, the relatively low solvophobicity between RTILs and the hydrophobic tail of surfactant could contribute to high Critical Micelle Concentration (CMC). The CMC point can be observed from a plot of graph of

Corresponding Author: Muhammad Alif Mohammad Latif, Center of Foundation Studies for Agricultural Science, Universiti Putra Malaysia (UPM), 43400 Serdang, Selangor, Malaysia, aliflatif@upm.edu.my 


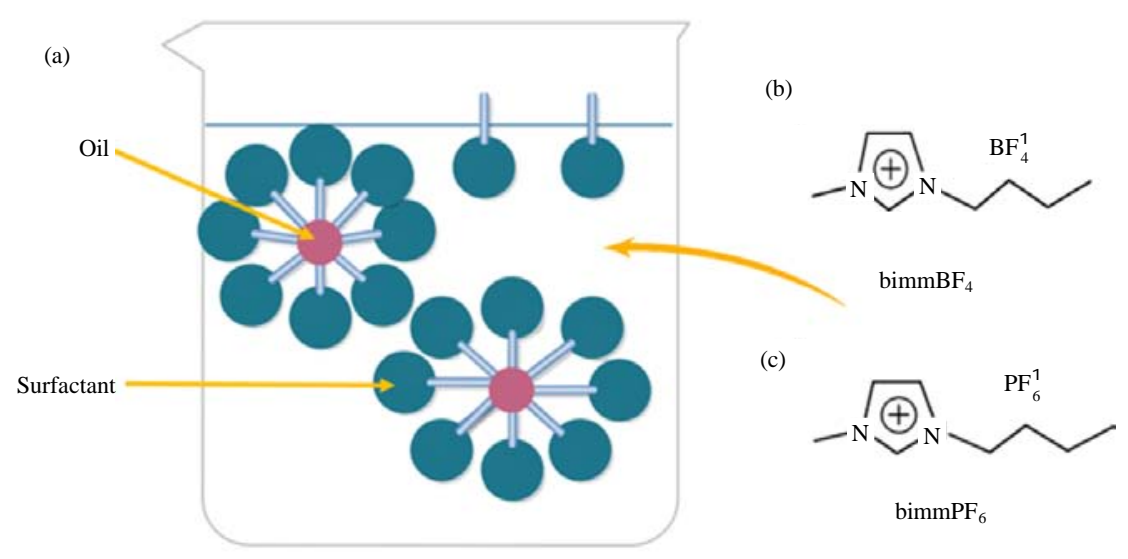

Fig. 1: a) Schematic representation of oil-in-RTILs nanoemulsions and the chemical structures of; b) $b_{m i m B F}$ and c) bmimPF RTILs $^{2}$

surface tension versus the concentration of the surfactant (Chen, 2015). The abrupt change in the slope point to the minimum concentration of surfactant needed to form micelles. Jin et al. (2015) reported the use of 1-butyl-3-metylimidazolium hexafluorophosphate $\left(\mathrm{bmimPF}_{6}\right)$ as the media for the self-aggregation of polyoxyethylene glycol dodecyl ethers (Brij 35) non-ionic surfactants. The results showed that addition of surfactants would decrease the surface tension of RTIL. The other major factor that would dictate the self-aggregation of amphiphilic molecules in RTILs is the hydrophobic effect, since, the hydrophobic tail of surfactants dislikes water and the system wants to decrease the number of unfavourable interactions between the hydrophobic tail of RTILs and water (Piran et al., 2017). The ability to support surfactant aggregation makes the applications for the RTILs become wider as the case for drug delivery (Moniruzzaman et al., 2010a, b; Dobler et al., 2013; Goindi et al., 2015; Monti et al., 2017) and separation process (Guzman-Lucero et al., 2010; Lemos et al., 2010 ; Pius, 2014; Arain et al., 2016; Makanyire et al., 2016; Balsamo et al., 2017). Traditionally, the use of the volatile organic solvent for the separations processes can cause environmental hazard (Pruthu, 2014). For example in the petroleum industry, the uses of volatile organic solvent such as alcohols and ethers in separation process showed negative effects towards the environment (Dharaskar et al., 2013). These problems can be alleviated using RTILs as the media, since, most RTILs are characterized as "green" solvents (Martinez-Palou and Sanche, 2011).

This study is mainly focused on the surfactant aggregation in RTILs and the effect of adding an oil phase to the system, essentially forming nanoemulsions. Nanoemulsion is normally oil-in-water dispersions. The particles size of nanoemulsion varies in the literature and the study from Jafari et al. (2006) showed that the droplet size for nanoemulsion could fall in the range of $150-700 \mathrm{~nm}$ depends on the methods used. In addition, many published research works showed variations in the size of the nanoemulsion from $20-300 \mathrm{~nm}$. In this project, the added oil phase should induce the formation of oil-in-RTIL nanoemulsion aggregates. RTILs are immiscible with the oil phase. Thus, the formation of the oil-in-RTL nanoemulsion can overcome the solubility limitation of the RTLs in the immiscible phase (Gao et al., 2008a, b).

The anion species in the RTILs structure can have a profound effect on the surfactant aggregation behaviour. It was found that using different types of anions led to different micellar sizes and aggregation numbers (Patrascu et al., 2006). Here, two RTILs with different anions were used (Fig. 1). They were bmimPF and 1-butyl-3-methylimidazolium tetrafluoroborate (bmimBF ${ }_{4}$ ). Polysorbate 80 (Tween80) (Aizawa, 2009) was used as the non-ionic surfactant and Palm Oil Ester (POE) as the oil phase. POEs are mixture of several types of esters including oleyl laurate (C30:1) (0.4\%), oleyl myristate (C32:1) (2.6\%), oleyl palmitate (C34:1) (42.1\%), oleyl stearate (C36.1) (5.3\%), oleyl oleate (C36:2) (31.7\%) and oleyl linoleate (C36:3) (10.2\%) (Gunawan et al., 2004). The CMC of Tween 80 in both RTILs were determined by surface tension measurements while the resulting binary and ternary phases were characterized by Zetasizer measurements and Transmission Electron Microscopy (TEM).

\section{MATERIALS AND METHODS}

Chemicals and reagents: POE was prepared in the laboratory using the method from Gunawan et al. (2004). 
Table 1: Phy sical properties of water and RTILs at room temperature

\begin{tabular}{lccc}
\hline Variables & MW $(\mathrm{g} / \mathrm{moL})$ & Density $(\mathrm{g} / \mathrm{mL})$ & Surfacetension $\left(\mathrm{mNm}^{-1}\right)$ \\
\hline Water & 18.01 & 1.00 & 72 \\
BmimPF $_{6}$ & 284.18 & 1.38 & 54 \\
BmimBF$_{4}$ & 226.02 & 1.21 & 52 \\
\hline
\end{tabular}

$\mathrm{BmimPF}_{6}$ and bmimBF $\mathrm{b}_{4}$ were purchased from Sigma, China. The viscosity, density, molecular weight and the surface tension of the pure RTILs at room temperature are listed in Table 1. To remove any impurities, both RTILs were dried and heated at $70^{\circ} \mathrm{C}$ and was put in the vacuum for 2 days. Tween 80 was obtained from Sigma-Aldrich. The surfactants were used as received. For the water phase, the deionized water prepared in the laboratory was used.

\section{Procedure}

Effect of surfactant concentration to the CMCs of the binary phases: The deionized water was used to dissolve Tween 80 and then heated to $50^{\circ} \mathrm{C}$. The $3.0 \mathrm{~mL}$ of bmimPF$_{6}$ and bmimBF$_{4}$ was put into different glass vials. Then, different concentrations of Tween 80 were added drop-wise into the RTILs to study the effect of the concentration of the surfactant to the surface tension. Next, the mixture of the RTILs and Tween 80 was stirred using the magnetic stirrer until homogenous solution was obtained. Surface tension was measured after an equilibrium time of $15 \mathrm{~min}$. Different concentrations of Tween 80 were added drop-wise into deionized water to compare the surface tension of RTILs and aqueous solution. The surface tension was measured for three times to get the average surface tension value. The CMC was obtained after constant reading of surface tension was obtained.

Preparation of palm-based nanoemulsion in RTILs: The surfactant/RTIL/oil nanoemulsions were prepared using the low energy method. The POE weight fraction, F (where $\mathrm{F}=\mathrm{W}_{\text {oil }} /\left(\mathrm{W}_{\text {oil }}+\mathrm{W}_{\text {surfactant }}+\mathrm{W}_{\mathrm{IL}}\right)$ ) used was fixed to 0.10 while the surfactant weight fraction, $\mathrm{R}$ (where $\mathrm{R}=$ $\left.\mathrm{W}_{\text {surfactant }} /\left(\mathrm{W}_{\text {surfactant }}+\mathrm{W}_{\mathrm{IL}}\right)\right)$ used was fixed to 0.5 . This is decided based on the previously obtained CMCs. For surfactant/water/oil nanoemulsion, the POE weight fraction, $\mathrm{F}$ (where $\mathrm{F}=\mathrm{W}_{\mathrm{oil}} /\left(\mathrm{W}_{\text {oil }}+\mathrm{W}_{\text {surfactant }}+\mathrm{W}_{\text {water }}\right.$ )) used was fixed to 0.10 with surfactant weight fraction and $\mathrm{R}$ (where $\left.\mathrm{R}=\mathrm{W}_{\text {surfactant }} /\left(\mathrm{W}_{\text {surfactant }}+\mathrm{W}_{\text {water }}\right)\right)$ used was 0.2 . The mixtures were left for $30 \mathrm{~min}$ under magnetic stirring (600 rpm) at $25^{\circ} \mathrm{C}$ to mix thoroughly. Then, POE was added drop-wise while mixing with the aid of overhead stirrer at $600 \mathrm{rpm}$ and temperature of $25^{\circ} \mathrm{C}$. This method with is based on the low energy method, let the droplet size of the emulsion occurred spontaneously. The resulting nanoemulsions were kept at room temperature to check its stability.

\section{Characterization}

Zetasizer: Zetasizer Nano ZS (Malvern Instruments Ltd., UK) was used to measure the particle size, zeta potential and Polydispersity Index (PDI) of the system. This instrument was based on dynamic light scattering method. The software used was Dispersion Technology Software Nano Version 5.03 (Malvern Instruments Ltd.). Deionized water was used to dilute the sample for each measurement. Dynamic light scattering detected the dispersion of particle moving under Brownian motion and the average size changed to size distribution by using the Stokes-Einstein relationship:

$$
\mathrm{D}_{\mathrm{h}}=\frac{\mathrm{k}_{\mathrm{B}} \mathrm{T}}{3 \pi \eta \mathrm{D}_{\mathrm{t}}}
$$

Where:

$\mathrm{D}_{\mathrm{h}}=$ The hydrodynamic Diameter

$\mathrm{D}_{\mathrm{t}}=$ The translational Diffusion coefficient

$\mathrm{k}_{\mathrm{B}}=$ Boltzmann's constant

$\mathrm{T}=$ The Thermodynamic temperature

$\eta=$ The viscosity

Zeta potential is a measurement of the electrostatic potential at the electrical double layer surrounding a nanoparticle in a mixture. Zeta potential values play an important role to determine whether the nanoemulsion form can permeate membrane or vice versa. The electrical field was applied to the solution and the electrophoteric mobility, $\mathrm{U}_{\mathrm{E}}$ was measured. The zeta potential, $\zeta$ was then derived from Henry's equation:

$$
\mathrm{U}_{\mathrm{E}}=\frac{2 \varepsilon \zeta}{3 \eta} \mathrm{f}(\mathrm{ka})
$$

Where:

$\varepsilon \quad=$ The dielectric constant

$\eta \quad=$ The absolute zero-shear viscosity of the medium $\mathrm{f}(\mathrm{ka})=$ The Henry's function

a $=$ Measure of the ratio of the particle radius of the Debye length

Deionized water was used to dilute $0.5 \mathrm{~mL}$ of a sample before each measurement.

Transmission electron microscopic: The morphology and structure of Tween80 aggregation in RTILs and the nanoemulsion were studied using TEM, LEO 912AB EFTEM. To perform the TEM observations, the sample was first diluted with deionized water to $1.0 \mathrm{~mL}$ solution. Then, the diluted solutions were placed on a formvar carbon-coated copper grid (200 mesh/in) and then stained with $1 \%$ phosphotungstic acid. The excess phosphotungstic acid on the sample was gently wiped using filter paper and examined after drying for about one day at room temperature. 

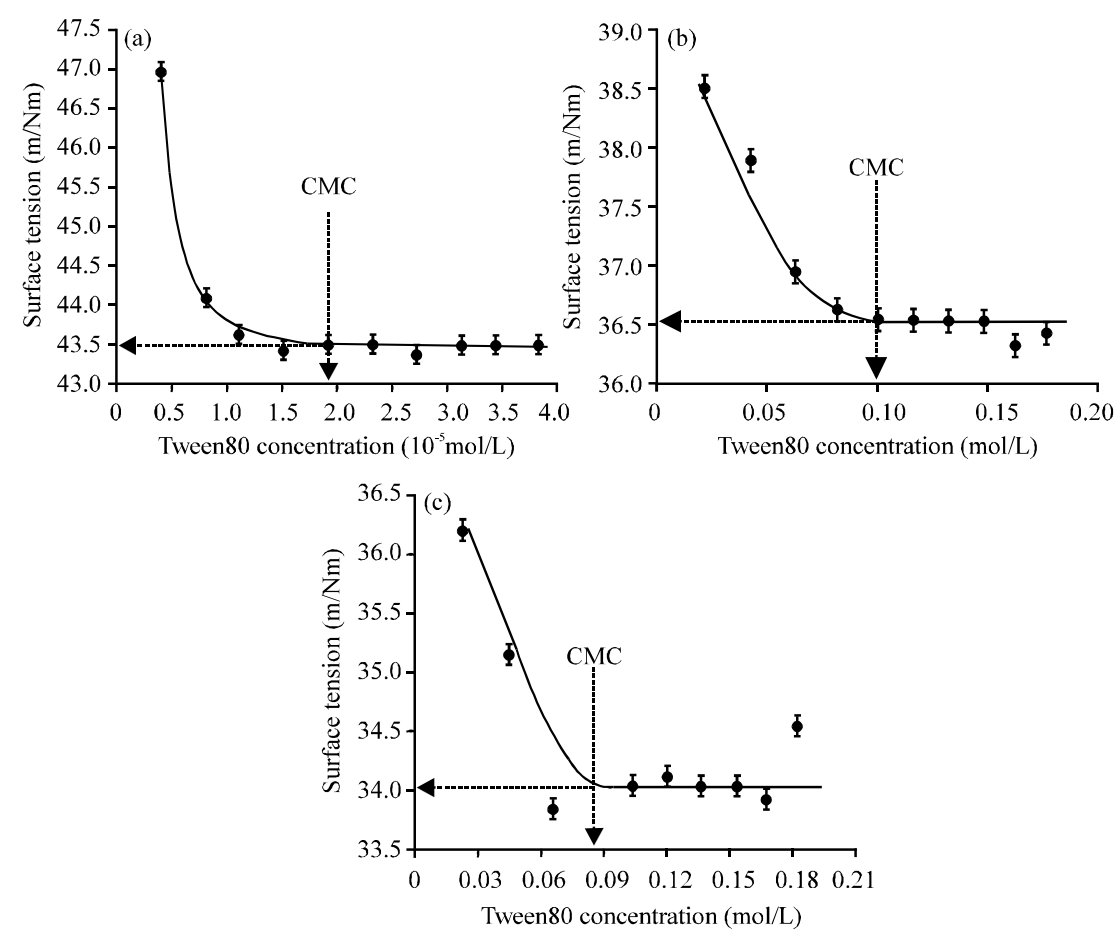

Fig. 2: Plot of surface tension vs. Tween 80 concentration for: a) Tween $80 /$ water; b) Tween $80 / \mathrm{bmimPF}_{6}$ and c) Tween $80 / \mathrm{bmimBF}_{4}$

\begin{tabular}{lccc} 
Table 2: Results from Zetasizer Nano ZS \\
$\begin{array}{l}\text { Particle } \\
\text { size (nm) }\end{array}$ & $\begin{array}{c}\text { Poly dispersity } \\
\text { Index (PDI) }\end{array}$ & $\begin{array}{c}\text { Zeta potential } \\
\text { (mV) }\end{array}$ \\
\hline Tween phoses & 18.860 & 0.393 & -11.590 \\
Tween $80 / \mathrm{bmimPF}_{6}$ & 153.100 & 0.412 & -14.900 \\
Tween80/bmimBF $_{4}$ & 58.230 & 0.393 & -8.320 \\
\hline
\end{tabular}

\section{RESULTS AND DISCUSSION}

Surface tension of the binary phases: From the surface tension measurements, it was found that the initial surface tension of the $\mathrm{bmimPF}_{6}$ and $\mathrm{bmimBF}_{4}$ were lower than that for pure water (Table 2). The results from each measurement for the binary phases were illustrated in three different plots (Fig. 2). There was an abrupt change in the slope of surface tension observed as the surfactant concentration increases. After this point, the surface tension of the RTILs solutions remained consistent which indicated the formation of micelles within the water and RTILs. The turning point for each plot corresponds to the CMC of the mixture. The surface tension of Tween 80/bmimPF F $_{6}$ (Fig. 2b) was decreased from 38.4-36.5 $\mathrm{m} / \mathrm{Nm}$ in comparison with solution of Tween $80 / \mathrm{bmimBF}_{4}$ (Fig. 2c) that showed decrement in surface tension from $36.1-34.0 \mathrm{~m} / \mathrm{Nm}$. The change in surface tension exhibited their adsorption at the air-solution interface (Gao et al., 2006, 2008a, b; Abdellatif and Abou-Taleb, 2016). The number of molecules present at the surface or as micelles in the solution depends on the concentration of Tween80. From the surface tension measurements, the CMCs of Tween80 in water in bmimPF 6 and in bmimBF ${ }_{4}$ were determined around $1.90 \times 10^{-5}, 0.100$ and $0.082 \mathrm{~mol} / \mathrm{L}$, respectively. The $\mathrm{CMC}$ for all binary phases were in good agreement considering that bmimPF${ }_{6}$ is the most viscous $(382 \mathrm{cP})$, followed by bmimBF $\mathrm{Bm}_{4}(132 \mathrm{cP})$ and water $(1 \mathrm{cP})$ which has the lowest viscosity among the three (Tomida et al., 2006). Besides as is well known, RTILs have a relatively higher density than water. The density of bmimPF $F_{6}$ and bmimBF${ }_{4}$ are 1.21 and $1.38 \mathrm{~g} / \mathrm{mL}$ in comparison with water that has the density of $1.00 \mathrm{~g} / \mathrm{mL}$ (Fredlake et al., 2004; Gardas et al., 2007). The significantly higher CMCs observed in RTILs demonstrate a case of slower micellization compared to the ones in water (Abdellatif and Abou-Taleb, 2016). These results also exhibited the lower solvophobicity of RTILs with means that the driving force of micelle formation was weaker and leads to the slower association of surfactant molecules in RTILs. This phenomenon was also observed from our previous computer simulations (Latif and Rahman, 2018). Molecular dynamics simulations on the same systems showed that the self-aggregation of Tween80 in both RTILs was significantly slower than in water. 

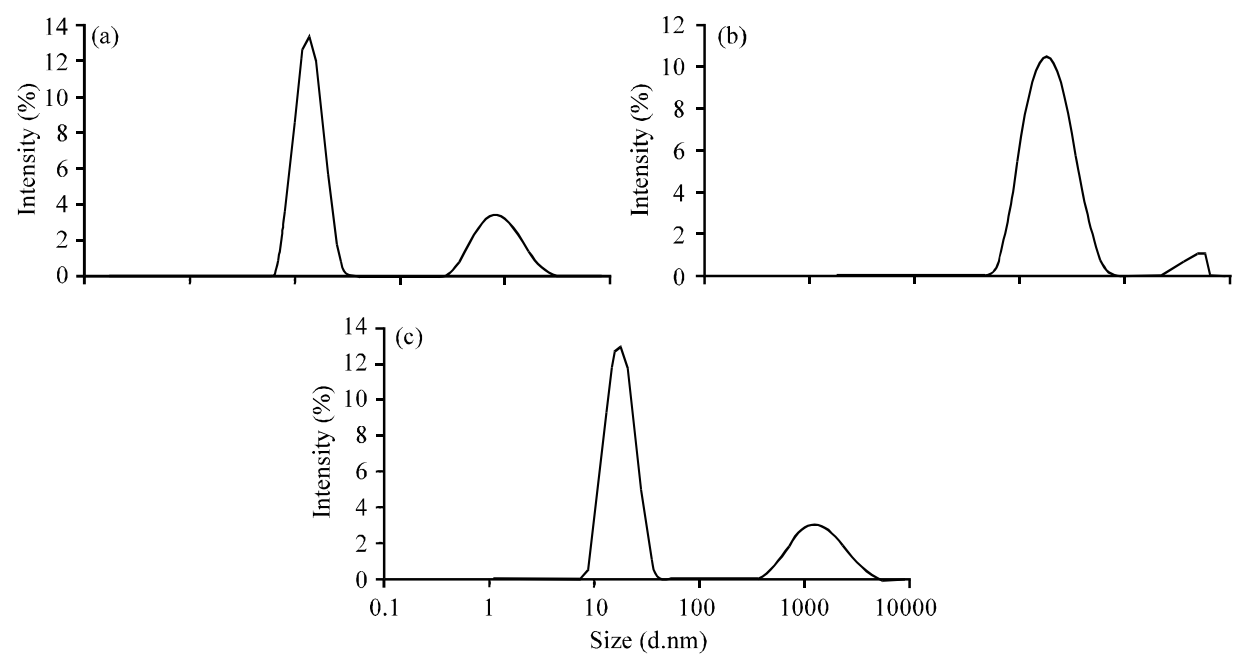

Fig. 3: Size distribution for: a) Tween $80 /$ water; b) Tween $80 / \mathrm{bmimPF}_{6}$ and c) Tween $80 / \mathrm{bmimBF}_{4}$ micellar solution

\section{Characterization of the binary phases}

Zetasizer: From the Zetasizer results, it was observed that the size of Tween 80 aggregates in RTILs was higher compared to water with had only $18.86 \mathrm{~nm}$ in size. This result showed that the solvophobicity between RTILs and the hydrophobic tail of surfactants is lower than that between water and the hydrophobic tail of surfactant. This is also in accordance with the fact that RTILs have a polarity similar to short chain alcohols (Gao et al., 2008). As previously shown, the CMCs of Tween 80 in RTILs were significantly higher than in water. Higher $\mathrm{CMCs}$ meant higher number of Tween 80 molecules were needed to form self-aggregated structures. Such high surfactant concentration would also contribute to a crowded structure and large-sized cluster aggregates. The Zetasizer measurements results also give the value for the Polydispersity Index (PDI) and the zeta potential. The PDI values ranging from 0.1-0.25 indicated a narrow size distribution while a PDI $>0.5$ indicated broad distribution (Piran et al., 2017). The PDI for all solution that shown in Table 2 were all below 1.0. PDI results also represent size distribution range in colloidal solution. High PDI indicates the heterogeneity of the particle size in suspension while smaller PDI values indicate the homogeneity of the particle size in suspension (Abdellatif and Abou-Taleb, 2016).

Figure 3 showed that the size distribution for Tween $80 / \mathrm{bmimPF}_{6}, \mathrm{Tw}$ ween $80 / \mathrm{bmimBF}_{4}$ and Tween $80 /$ water aggregates were different from each other. From the size distribution results, it showed that there were two peaks in different sizes or bimodal. The size distribution result is also related to the span value, the particle distributions. Low span values indicate a narrowed particles size distribution (more homogeneous sizes).
Thus, solution of Tween $80 /$ water and Tween $80 / \mathrm{bmimBF}_{4}$ (Fig. 3a, c) were considered more homogeneous because it presented a narrower particle size distribution than Tween $80 / \mathrm{bmimPF}_{6}$. This can be attributed to the fact that water is essentially polar while bmimBF 4 is more hydrophilic than bmimPF $_{6}$. In agreement, the PDI results for Tween $80 /$ water and Tween $80 / \mathrm{bmimBF}_{4}$ mixture $(0.393)$ were lower in comparison with PDI value for Tween $80 / \mathrm{bmimPF}_{6}$ with is 0.412 . As can be seen in Table 2, Tween 80 -based micellar solution produced a droplet size of below $200 \mathrm{~nm}$ and had satisfactory zeta potential values. Higher zeta potential (negative or positive) indicates higher stability of colloid dispersions (Greenwood and Kendall, 1999). The zeta potential distribution results for Tween $80 / \mathrm{bmimPF}_{6}$, Tween80/ bmimBF$_{4}$ and Tween $80 /$ water showed uniform peaks. This is also an indication of stable formulations. Although, bigger in particle size, the zeta potential results showed that Tween 80 aggregate was most stable in bmimPF ${ }_{6}$, most likely due to the hydrophobic nature of the RTIL. The hydrophobic effect was stronger and therefore, the selfaggregated structures in $\mathrm{bmimPF}_{6}$ has less tendency to dissociate.

Transmission electron microscopy: Figure 4-6 show TEM images of the Tween 80 micelles formed in water, bmimPF$_{6}$ and $\mathrm{bmimBF}_{4}$, respectively, each at Tween 80 concentration above CMC. For Tween $80 / \mathrm{bmimPF}_{6}$, irregular droplet micellar particles of about $70 \mathrm{~nm}$ were formed and some larger cluster aggregates formed by the combination of independent irregular micellar particles. These results agreed with Zetasizer measurements with showed that the average size for Tween $80 / \mathrm{bmimPF}_{6}$ could reach up to $153.1 \mathrm{~nm}$. The average micellar size, 
(a)

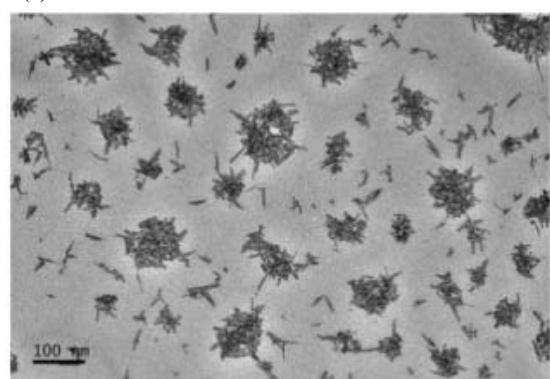

(c)

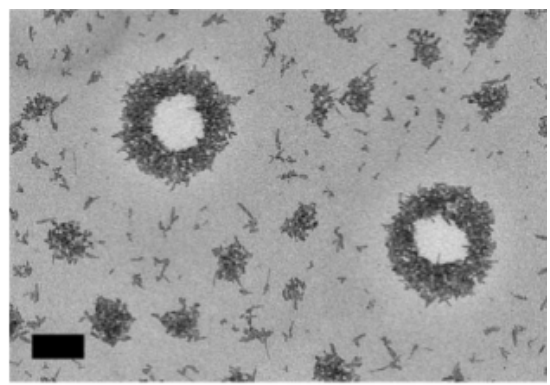

(b)

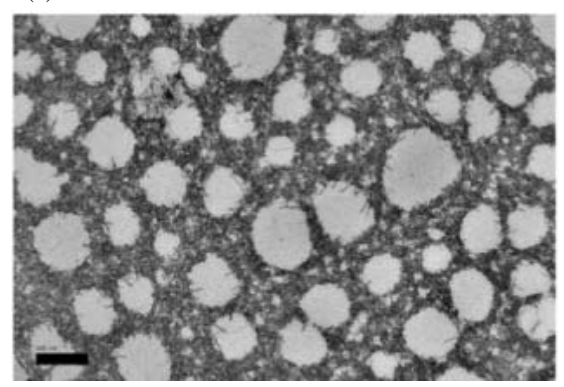

(d)

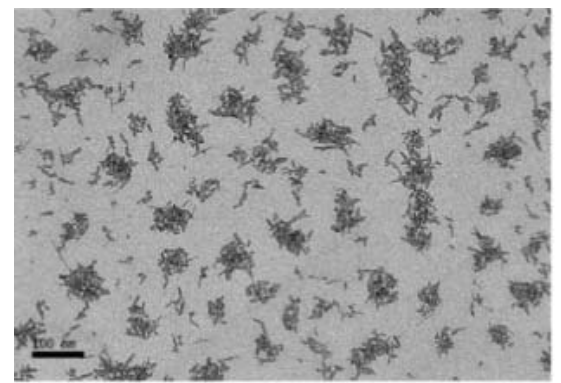

Fig. 4: a-d) TEM image of Tween80/water micellar solution

(a)

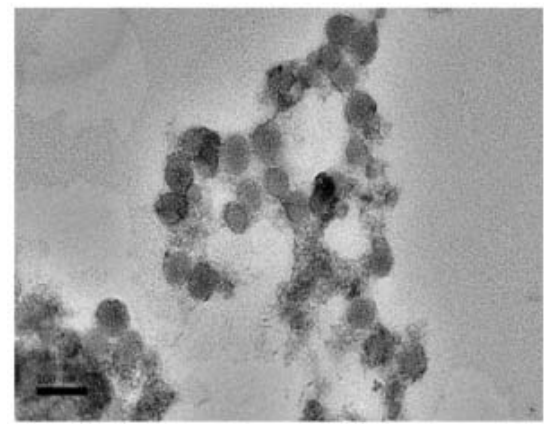

(c)

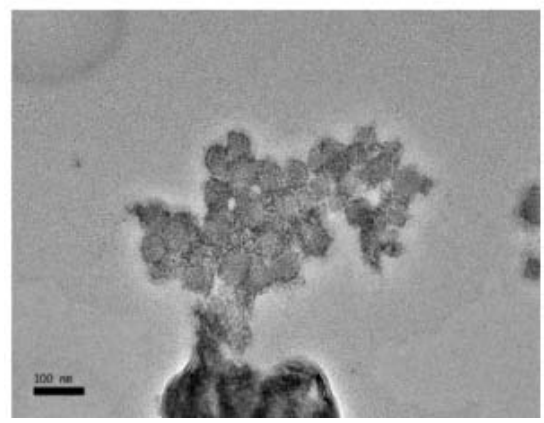

(b)

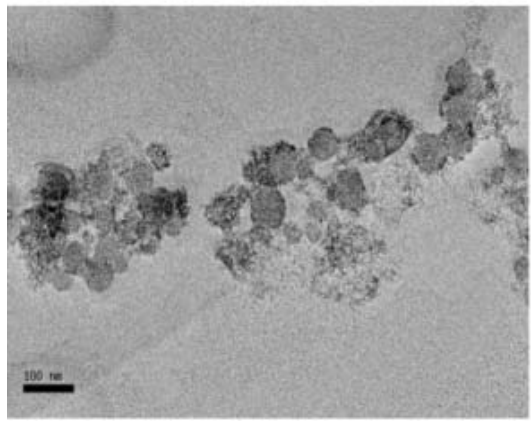

(d)

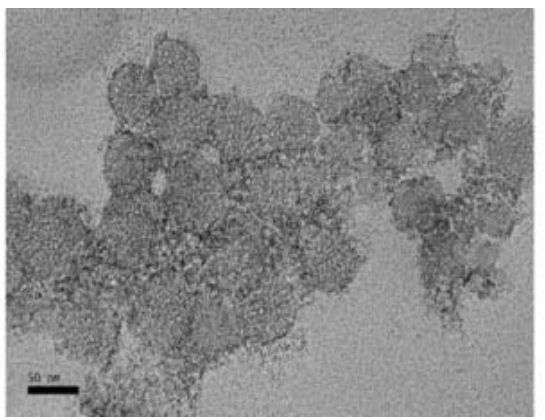

Fig. 5: a-d) TEM image of Tween $80 / \mathrm{bmimPF}_{6}$ micellar solution

either independent micellar particles or crowded larger aggregates was much larger than the aqueous Tween 80 micelles with have a general size of below $18.86 \mathrm{~nm}$ based on the particle size results. The irregular aggregate structure for RTILs was also different from the common aqueous micelles that have a typical spherical-to-ellipsoidal shapes. This was because RTILs have a relatively higher density and viscosity than water 
(a)

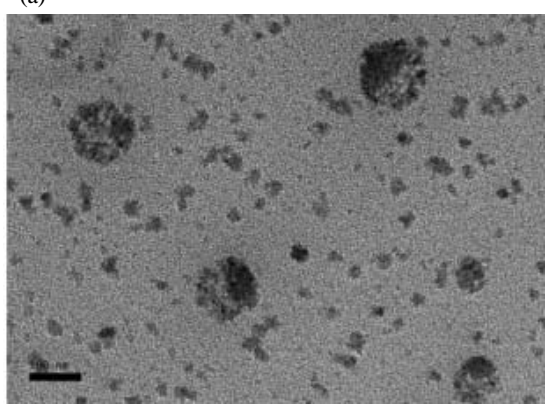

(c)

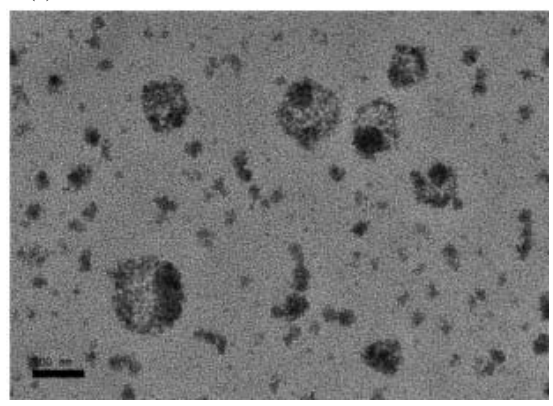

(b)

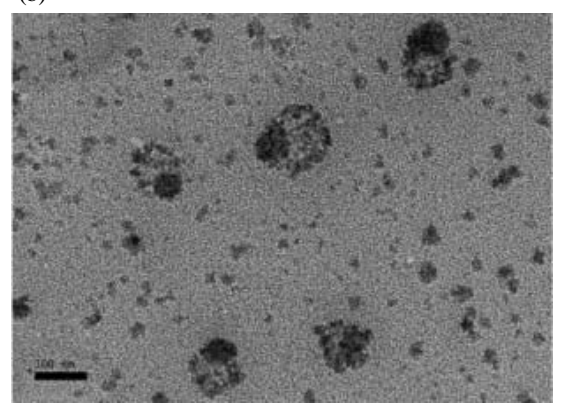

(d)

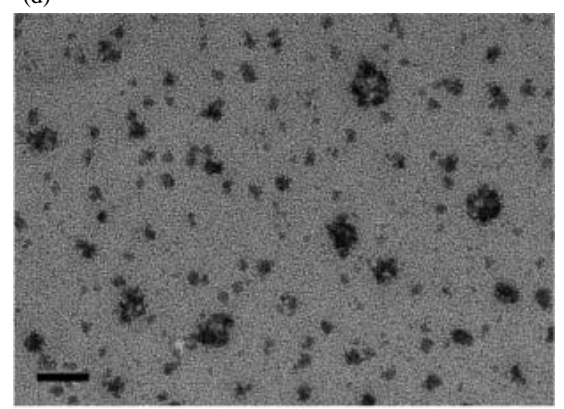

Fig. 6: a-d) TEM image of Tween $80 / \mathrm{bmimBF}_{4}$ micellar solution

as a result, the formed micelles were somewhat compressible in RTILs in comparison with water, especially considering that surfactant molecule has a flexible long chain. This also means that they can be easily deformed (Gao et al., 2008a, b).

For the micelles to form in RTILs, the concentration of the surfactant needed was higher which was more than $0.100 \mathrm{~mol} / \mathrm{L}$. The higher surfactant concentration also, caused larger aggregates and crowded structures to form. The effective area of interaction for non-ionic surfactants was much higher in $\mathrm{bmimBF}_{4}$ than water because of the larger size and multi-interaction sites of RTILs. The high effective area prefers to cause an extended conformation of chain of Tween80, thus, results in the appearance of very large aggregations. The large-sized RTILs binding hydrophilic chain of Tween 80 can lead to a dumpy bulk of surfactants with will form micelles with a large micellar diameter. Furthermore, the lower solvophobicity caused a very high $\mathrm{CMC}$ and high surfactant concentration may cause the appearance of large micellar bulk.

\section{Formulation of palm-based nanoemulsions involving in} RTILs: Table 3 shows that the particle size of formulations containing Tween $80 /$ water/POE and Tween $80 / \mathrm{bmimBF}_{4} / \mathrm{POE}$ were 239.2 and $237.5 \mathrm{~nm}$, respectively which were lower than the nanoemulsion of Tween $80 / \mathrm{bmimPF}_{6} / \mathrm{POE}$. Note that all formulations consisted of the same amount of surfactant, RTILs and POE. From the Zetasizer result, it showed that the addition
Table 3: Results from Zetasizer Nano ZS

\begin{tabular}{lccc}
\hline Ternary phases & $\begin{array}{c}\text { Particle } \\
\text { size }(\mathrm{nm})\end{array}$ & $\begin{array}{c}\text { Polydispersity } \\
\text { Index }(\mathrm{PDI})\end{array}$ & $\begin{array}{c}\text { Zeta potential } \\
(\mathrm{mV})\end{array}$ \\
\hline Tween80/water/POE & 239.2 & 0.438 & -20.93 \\
Tween $80 / \mathrm{bmimPF}_{6} / \mathrm{POE}$ & 295.2 & 0.301 & -20.50 \\
Tween $80 / \mathrm{bmimBF}_{4} / \mathrm{POE}$ & 237.5 & 0.336 & -21.33 \\
\hline
\end{tabular}

of oil provided a strong hydrophobic environment for the hydrophobic groups of Tween80 molecules and induced them to aggregate into interface film. The zeta potential for all formulations was increased with the addition of oil phase indicating higher stability (Greenwood and Kendall, 1999). The results also indicated that $\mathrm{Tween} 80 / \mathrm{bmimBF}_{4} / \mathrm{POE}$ was more suited for further use in separation process, since, it has smaller particle size (closely similar to aqueous nanoemulsion) with an acceptable PDI value and zeta potential near $-30 \mathrm{mV}$.

Transmission electron microscopy: The TEM results (Fig. 7 and 8) were different from the ones that observed in the binary phases without POE. Based on the micrographs, it was observed that when POEs were added to the Tween 80 based RTILs solution, new self-aggregated structures were formed. As mentioned previously in RTILs is was more difficult for Tween 80 molecules to aggregate into larger micelles due to their weak solvophobicity. After adding POEs, the oil phase was dispersed and induced the formation of Tween 80 aggregates. In other words, the POEs provide a stronger apolar environment and caused the hydrophobic tails of Tween80 to aggregate together. In 
(a)

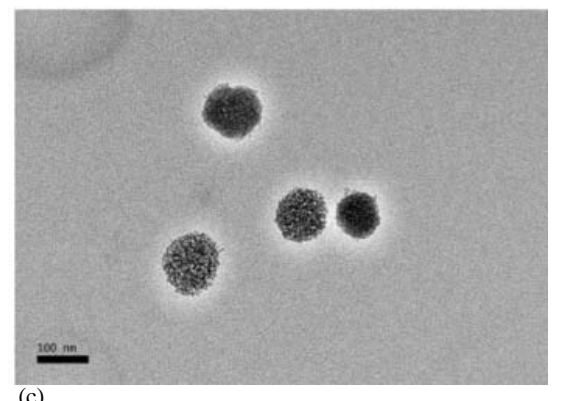

(c)

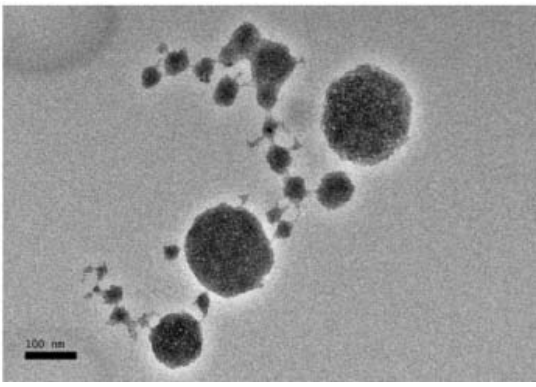

(b)

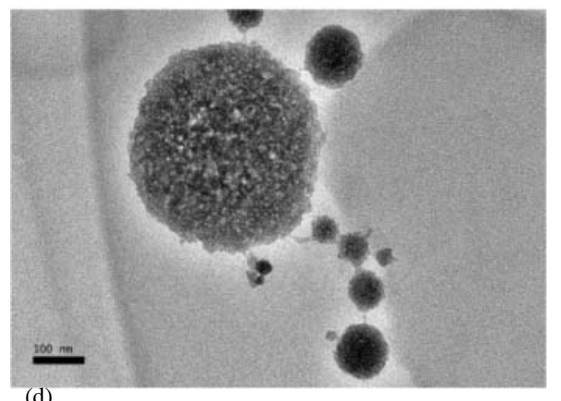

(d)

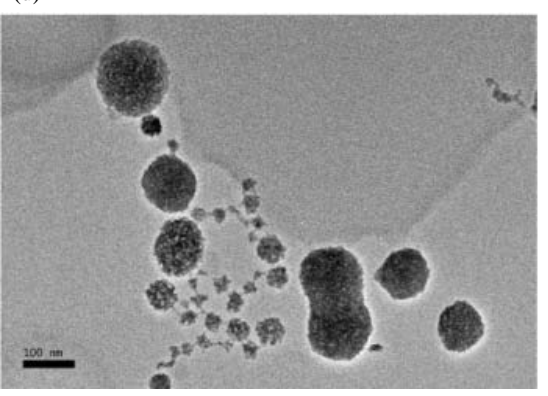

Fig. 7: a-d) TEM image of Tween80/bmimPF $/$ /POE nanoemulsion

(a)

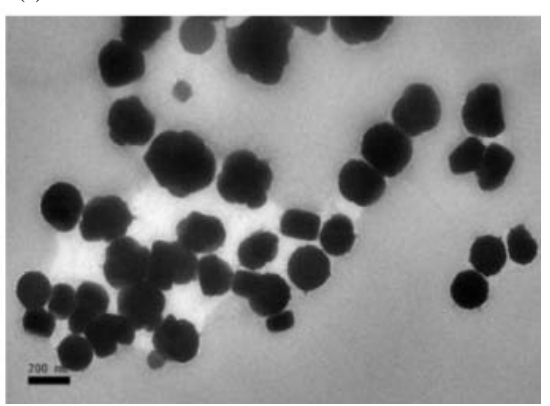

(c)

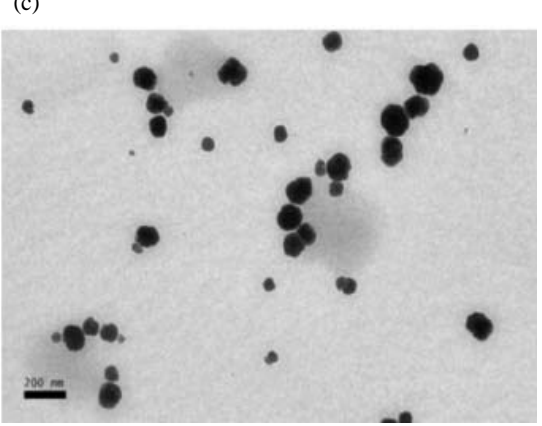

(b)

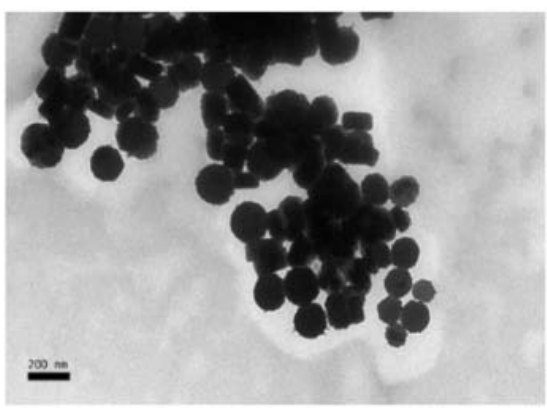

(d)

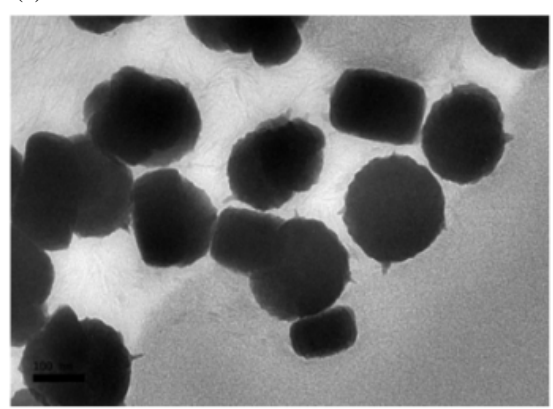

Fig. 8: a-d) TEM image of Tween $80 / \mathrm{bmimBF}_{4} / \mathrm{POE}$ nanoemulsion

these aggregates, POEs dispersed as apolar cores and Tween80 molecules were separated (Jin et al., 2015).

In the TEM image for Tween $80 / \mathrm{bmimBF}_{4} / \mathrm{POE}$ (Fig. 8), the nanoemulsion appeared dark and the surroundings were bright. The micrograph shows that the droplets size of the sample was in the range for a nanoemulsion system (Jafari et al., 2006). Based on the Fig. 7 and 8, Tween 80 molecules were well dispersed when the POE was added. Higher aggregation number of Tween 80 can be seen for the formulation containing Tween $80 / \mathrm{bmimBF}_{4} / \mathrm{POE}$ compared to the Tween $80 /$ bmimPF $F_{6} / \mathrm{POE}$ nanoemulsion. This result was comparable with the particle size results (Table 3) which 
showed that the formulation of Tween $80 / \mathrm{bmimPF}_{6} / \mathrm{POE}$ nanoemulsion were bigger in size compared to Tween $80 /$ bmimBF $/ \mathrm{POE}$ and Tween $80 /$ water/POE nanoemulsion. However, the size fraction of large droplet varied between each emulsion. For the hydrophobic bmimPF 6 , some aggregates were significantly bigger due to stronger hydrophobic effect. For bmimBF 4 which is more hydrophilic, the size distribution was more even.

\section{CONCLUSION}

The self-aggregation behaviour of non-ionic surfactant, Tween 80 in two different imidazolium based

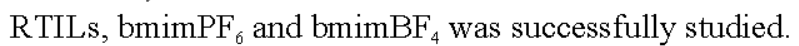
Based on the result from tensiometer, Zetasizer and TEM, it was shown that the surfactants were able to aggregate and formed micellar solution in both RTILs like the aqueous solution. The $\mathrm{CMC}$ results also corroborate our previous computer prediction that the weak solvophobicity of RTILs caused slower formation of aggregated structures. Tween $80 / \mathrm{bmimPF}_{6}$ and Tween $80 / \mathrm{bmimBF}_{4}$ were then used to formulate the nanoemulsion with the addition of POE as the oil phase. These nanoemulsions were successfully formed using low energy emulsification method. The results from the particle size measurement showed that Tween $80 / \mathrm{bmimBF}_{4} / \mathrm{POE}$ and $\mathrm{Tween} 80 / \mathrm{bmimPF}_{6} / \mathrm{POE}$ nanoemulsions have a particle size of 237.5 and 295.2 $\mathrm{nm}$ respectively. The particle size of Tween $80 / \mathrm{bmimBF}_{4} /$ $\mathrm{POE}$ was found comparable to the Tween $80 / \mathrm{water} / \mathrm{POE}$ nano-emulsions $(239.2 \mathrm{~nm})$. The introduction of oil phase produced a diverse effect towards hydrophobic and hydrophilic RTILs. A more hydrophobic bmimPF produced uneven size distribution while a more

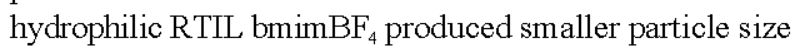
and better dispersions of the self-aggregated structures.

\section{ACKNOWLEDGEMENT}

The research leading to these results were funded by UPM Research University Grant, GP-IPM/201 5/9456100. All research works conducted at the Department of Chemistry, Faculty of Science, Universiti Putra Malaysia.

\section{REFERENCES}

Abdellatif, A.A. and H.A. Abou-Taleb, 2016. Transfersomal nanoparticles of keratolytic and antibacterial agents for enhanced transdermal delivery. J. Nanotechnol. Adv. Mater., 4: 19-23.

Aizawa, H., 2009. Morphology of polysorbate 80 (Tween 80 ) micelles in aqueous 1,4-dioxane solutions. J. Appl. Crystallogr., 42: 592-596.
Arain, S.A., T.G. Kazi, H.I. Afridi, M.S. Arain and A.H. Panhwar et al., 2016. A new dispersive liquid-liquid microextraction using ionic liquid based microemulsion coupled with cloud point extraction for determination of copper in serum and water samples. Ecotoxicol. Environ. Saf., 126: 186-192.

Balsamo, M., A. Erto and A. Lancia, 2017. Chemical demulsification of model water-in-oil emulsions with low water content by means of ionic liquids. Braz. J. Chem. Eng., 34: 273-282.

Chen, L., 2015. Aggregation and interfacial behavior of charged surfactants in ionic liquids. Ph.D Thesis, University of Massachusetts Amherst, Massachusetts, USA.

Dharaskar, S.A., K.L. Wasewar, M.N. Varma, D.Z. Shende and C.K. Yoo, 2013. Deep removal of sulfur from model liquid fuels using 1-butyl-3-methylimidazolium chloride. Procedia Eng., 51: 416-422.

Dobler, D., T. Schmidts, I. Klingenhofer and F. Runkel, 2013. Ionic liquids as ingredients in topical drug delivery systems. Int. J. Pharm., 441: 620-627.

Flieger, J., E.B. Grushka and A. Czajkowska-Zelazko, 2014. Ionic liquids as solvents in separation processes. Austin J. Anal. Pharm. Chem., 1: 1-8.

Fredlake, C.P., J.M. Crosthwaite, D.G. Hert, S.N.V.K. Aki and J.F. Brennecke, 2004. Thermophysical properties of imidazolium-based ionic liquids. J. Chem. Eng. Data, 49: 954-964.

Gao, Y., A. Voigt, L. Hilfert and K. Sundmacher, $2008 \mathrm{~b}$. Nanodroplet cluster formation in ionic liquid microemulsions. Chem. Phys. Chem., 9: 1603-1609.

Gao, Y., N. Li, X. Li, S. Zhang and L. Zheng et al., 2008a. Microstructures of micellar aggregations formed within 1-butyl-3-methylimidazolium type ionic liquids. J. Phys. Chem. B., 113: 123-130.

Gao, Y.A., J. Zhang, H. Xu, X. Zhao and L. Zheng et al., 2006. Structural studies of 1-butyl-3methylimidazoliumtetrafluoroborate/TX-100/p-xylene ionic liquid microemulsions. Chemphyschem A. Eur. J. Chem. Phys. Phys. Chem., 7: 1554-1561.

Gardas, R.L., M.G. Freire, P.J. Carvalho, I.M. Marrucho and I.M. Fonseca et al., 2007. High-pressure densities and derived thermodynamic properties of imidazolium-based ionic liquids. J. Chem. Eng. Data, 52: $80-88$.

Goindi, S., R. Kaur and R. Kaur, 2015. An ionic liquid-in-water microemulsion as a potential carrier for topical delivery of poorly water soluble drug: Development, ex-vivo and in-vivo evaluation. Intl. J. Pharmaceutics, 495: 913-923.

Greaves, T.L. and C.J. Drummond, 2008. Ionic liquids as amphiphile self-assembly media. Chem. Soc. Rev., 37: 1709-1726. 
Greenwood, R. and K. Kendall, 1999. Selection of suitable dispersants for aqueous suspensions of zirconia and titania powders using acoustophoresis. J. Eur. Ceram.Soc., 19: 479-488.

Gunawan, E.R., M. Basri, M.B.A. Rahman, A.B. Salleh and R.N.Z.A. Rahman, 2004. Lipase-catalyzed synthesis of palm-based wax esters. J. Oleo Sci., 53: 471-477.

Guzman-Lucero, D., P. Flores, T. Rojo and R. Martinez-Palou, 2010. Ionic Liquids as demulsifiers of water-in-crude oil emulsions: Study of the microwave effect. Energy Fuels, 24: 3610-3615.

Jafari, S.M., Y. He and B. Bhandari, 2006. Nano-emulsion production by sonication and microfluidization: A comparison. Int. J. Food Prop., 9: 475-485.

Jin, Y., L. Wang, T. Wang, P. Chen and Y. Biet al., 2015. Aggregation behavior of dodecylsulfonate-based surface active ionic liquids in water. J. Mol. Liq., 212: 23-29.

Latif, M.A.M. and M.B.A. Rahman, 2018. Aggregation of Polysorbate 80 in room temperature ionic liquids investigated by molecular dynamics simulations. Sep. Purif. Technol., 196: 224-228.

Lemos, R.C., E.B. da Silva, A. dos Santos, R.C. Guimaraes and B.M. Ferreira et al., 2010. Demulsification of water-in-crude oil emulsions using ionic liquids and microwave irradiation. Energy Fuels, 24: 4439-4444.

Makanyire, T., S. Sanchez-Segado and A. Jha, 2016. Separation and recovery of critical metal ions using ionic liquids. Adv. Manuf., 4: 33-46.

Martinez-Palou, R. and P.F. Sanche, 2011. Perspectives of Ionic Liquids Applications for Clean Oilfield Technologies. In: Ionic Liquids: Theory, Properties, New Approaches, Kokorin, A. (Ed.). In Tech Open, USA., ISBN:9789533073491, pp: 567-628.

Moniruzzaman, M., M. Tamura, Y. Tahara, N. Kamiya and M. Goto, 2010b. Ionic liquid-in-oil microemulsion as a potential carrier of sparingly soluble drug: Characterization and cytotoxicity evaluation. Intl. J. Pharm., 400: 243-250.

Moniruzzaman, M., N. Kamiya and M. Goto, 2010a. Ionic liquid based microemulsion with pharmaceutically accepted components: Formulation and potential applications. J. Colloid Interface Sci., 352: $136-142$.
Monti, D., E. Egiziano, S. Burgalassi, P. Chetoni and C. Chiappe et al., 2017. Ionic liquids as potential enhancers for transdermal drug delivery. Intl. J. Pharm., 516: 45-51.

Patrascu, C., F. Gauffre, F. Nallet, R. Bordes and J. Oberdisse et al., 2006. Micelles in ionic liquids: Aggregation behavior of alkyl poly (ethyleneglycol)ethers in 1-butyl-3-methyl-imidazolium type ionic liquids. Chem. Phys. Chem., 7: 99-101.

Piran, P., H.S. Kafil, S. Ghanbarzadeh, R. Safdari and H. Hamishehkar, 2017. Formulation of menthol-loaded nanostructured lipid carriers to enhance its antimicrobial activity for food preservation. Adv. Pharm. Bull., 7: 261-268.

Pius, K.B., 2014. Extraction of dibenzothiophene from model oil using ionic liquids. Ph.D Thesis, Universiti Malaysia Pahang, Pahang, Malaysia.

Pruthu, K., 2014. Organic solvents-health hazards, national seminar on impact of toxic metals, minerals and solvents leading to environmental pollution. J. Chem. Pharm. Sci., 3: 83-86.

Shiddiky, M.J. and A.A. Torriero, 2011. Application of ionic liquids in electrochemical sensing systems. Biosens. Bioelectron., 26: 1775-1787.

Stockmann, T.J., P.D. Boyle and Z. Ding, 2017. Preparation and crystal structure of tetraoctylphosphonium tetrakis (pentafluorophenyl) borate ionic liquid for electrochemistry at its interface with water. Catal. Today, 295: 89-94.

Tomida, D., A. Kumagai, K. Qiao and C. Yokoyama, 2006. Viscosity of $[\mathrm{bmim}]\left[\mathrm{PF}_{6}\right]$ and $[\mathrm{bmim}]\left[\mathrm{BF}_{4}\right]$ at high pressure. Intl. J. Thermophys., 27: 39-47.

Vafaeezadeh, M. and H. Alinezhad, 2016. Bronsted acidic ionic liquids: Green catalysts for essential organic reactions. J. Mol. Liq., 218: 95-105.

Van Rantwijk, F. and R.A. Sheldon, 2007. Biocatalysis in ionic liquids. Chem. Rev., 107: 2757-2785.

Wang, Y., D. Zhao, L. Wang, X. Wang and L. Li, et al., 2018. Immobilized phosphotungstic acid based ionic liquid: Application for heterogeneous esterification of palmitic acid. Fuel, 2016: 364-370.

Wei, D. and A. Ivaska, 2012. Applications of ionic liquids in electrochemical sensors. Anal. Chim. Acta, Anal. Chim. Acta., 607: 126-135. 